\title{
Spinal Cord Electrical Stimulation for Refractory Angina Treatment
}

\section{Estimulação elétrica da medula espinal no tratamento da angina refratária}

\author{
Gustavo Veloso Lages ${ }^{1,2}$ Jose Oswaldo Oliveira Júnior $2,3 \odot$ \\ 1 Pain Ambulatory, Hospital da Santa Casa de Montes Claros e Hospital \\ Dilson Godinho, Montes Claros, MG, Brazil \\ ${ }^{2}$ Department of Atalgic Therapy, Functional Surgery, and Palliative \\ Care, Escola de Cancerologia Celestino Bourroul da Fundação \\ Antônio Prudente, São Paulo, SP, Brazil \\ ${ }^{3}$ Higher Council, Sociedade Brasileira para o Estudo da Dor, São Paulo, \\ SP, Brazil \\ Arq Bras Neurocir 2019;38:272-278.

\begin{abstract}
Address for correspondence Gustavo Veloso Lages, MD, Ambulatório de Dor, Hospital da Santa Casa Montes Claros, Montes Claros, MG, Brazil (e-mail: velosolages@hotmail.com).
\end{abstract}

\section{Abstract}

\section{Keywords}

- functional neurosurgery

- visceral pain

- chest angina

- angina pectoris

- unstable angina

- spinal cord electrical stimulation

\section{Resumo}

Cardiovascular disease (CVD) is the main cause of death worldwide, including in Brazil. Angina pectoris is a challenging disease because its clinical manifestation is not always related to the degree of obstruction. Visceral pain from any source can be totally disabling. It influences all aspects of the life of a patient and it can be one of the main causes of absence from work and of family disruption. Spinal cord electrical stimulation (SCES) has been traditionally applied for the treatment of neuropathic pain, with good to excellent results. Visceral pain syndrome can be as debilitating and disabling as somatic or neuropathic pain; however, there seems to be a lack of consensus on the appropriate treatment and strategies for these disorders. The major difference of SCES for visceral pain, compared to postlaminectomy syndrome or to regional complex syndrome, is the number of stimulated dermatomes. In most viscera, the somatotopic arrangement has two to four medullar levels, sometimes requiring laterality. After reviewing the literature, we have concluded that SCES is now a viable, low-risk option with satisfactory results for the treatment of neuropathic and visceral pain; therefore, it can be used in refractory angina after the failure of standard therapy. However, further studies are required to increase the application and efficacy of this procedure in the clinical practice.

A doença cardiovascular (DCV) é a principal causa de morte em todo o mundo, inclusive no Brasil. A angina do peito permanece como entidade clínica desafiadora devido ao fato de sua manifestação clínica nem sempre estar relacionada com o grau de obstrução. A dor visceral de qualquer origem pode ser totalmente incapacitante. Ela influencia todos os aspectos da vida de um paciente, podendo ser uma das principais causas de interrupção das received

June 13, 2016

accepted

August 30, 2016
DOI https://doi.org/

$10.1055 / \mathrm{s}-0036-1594256$. ISSN 0103-5355.
Copyright $\odot 2019$ by Thieme Revinter

Publicações Ltda, Rio de Janeiro, Brazil
License terms

(c) $(1) \$$ 


\section{Palavras-chave}

- neurocirurgia funcional

- dor visceral

- angina de peito

- angina pectoris

- angina instável

- estimulação elétrica da medula espinhal atividades laborais e da estrutura familiar. A estimulação elétrica da medula espinal (EEME) tem sido tradicionalmente aplicada para o tratamento de dor neuropática apresentando de bons a excelentes resultados. A síndrome de dor visceral pode ser tão debilitante e incapacitante quanto as dores somáticas ou neuropáticas; no entanto, parece haver uma falta de consenso sobre o tratamento adequado e as estratégias para estes transtornos. A grande diferença na estimulação medular para a dor visceral, em comparação com a síndrome pós-laminectomia ou com a síndrome complexa regional, é o número de dermátomos a serem estimulados. A grande maioria das vísceras tem somatotopia de dois a quatro níveis medulares, algumas das vezes necessitando de lateralidade. Após uma revisão da literatura, conclui-se que a EEME é hoje uma opção viável, de baixo risco e com resultados satisfatórios para o tratamento de dores de origem neuropática e visceral, portanto, passível de utilização na angina refratária, sendo indicada após a falha da terapia padrão. Porém, ainda há necessidade de mais estudos para maior empregabilidade e eficácia do procedimento na prática clínica.

\section{Introduction}

Cardiovascular disease (CVD) is the leading cause of death worldwide, including in Brazil. ${ }^{1}$ Data provided by the World Health Organization (WHO) show that CVD accounted for $\sim 17$ million deaths in 2011 (or $30.4 \%$ of all deaths in that year). ${ }^{2}$ In Brazil, according to data from the Department of Health, CVD accounted for $28.6 \%$ of all deaths in the country in 2011, and data from 2008 reported that circulatory system disorders were responsible for $80.2 \%$ of the hospitalizations of people $>50$ years old and for $10 \%$ of hospitalizations for all causes. ${ }^{3}$ Most deaths due to CVD are related to coronary artery disease (CAD) or to ischemic heart disease.

The most important heart diseases presenting with chest pain are ischemic heart diseases (stable angina, unstable angina, acute myocardial infarction) and noncardiac diseases (pericarditis, acute aortic and valvular dissection). ${ }^{4}$ It is estimated that between 5 to 8 million individuals with chest pain or with other symptoms suggestive of acute myocardial ischemia are seen in emergency rooms in the United States every year. ${ }^{5}$

Stable coronary artery disease, whose main clinical manifestation is angina pectoris, is characterized by reversible episodes of imbalance between blood supply and myocardial metabolic demand, usually inducible by physical exercise, emotion, or other types of stress; eventually, these episodes may be spontaneous. ${ }^{6}$

The various stable angina clinical presentations are related to several pathophysiological mechanisms, including: (1) epicardial coronary arteries obstruction by atherosclerotic plaques; (2) focal or diffuse vasospasm of coronary arteries; (3) microvascular disease; and (4) left ventricular dysfunction secondary to a previous myocardial infarction and/or to hibernating myocardium (chronic ischemia). Several of these processes can coexist in the same patient, contributing to the diversity of clinical manifestations associated with CAD. ${ }^{6}$

Angina pectoris remains a challenging clinical entity because its clinical manifestation is not always related to the degree of obstruction, being different in each patient, which results in a variety of clinical presentations: from completely asymptomatic to classical angina exertion-associated symptoms, refractory angina pain, and even sudden death. ${ }^{4}$

Visceral pain from any source can be totally disabling. It influences all aspects of the life of a patient and it can be one of the main causes of absence from work and of family disruption. ${ }^{7}$

The goal of chronic pain treatment is to improve quality of life; considering all of the aspects involved, this is a complex, arduous, and stressful task. When the goal is to improve viscerovascular pain, in addition to all of these adjectives, we can add challenging and laborious, since the pathophysiology is not fully understood yet. ${ }^{8}$

Treatment is always individualized, since its goal in an active and healthy patient is usually the complete elimination of pain and the return to vigorous physical activity. On the other hand, in an elderly patient with more severe angina and numerous associated comorbidities, a satisfactory result would be a reduction in symptoms, which would allow limited daily activities. ${ }^{8}$

The present paper searches for new techniques for pain control, reduction of suffering, and improvement of the quality of life for those with refractory angina.

\section{Refractory Angina and Spinal Cord Electrical Stimulation}

The classical chest pain in acute coronary syndrome is a painful, uncomfortable, burning or oppressive sensation located in the precordial or retrosternal region, which may irradiate to the shoulder and/or to the left arm, to the right arm, to the neck, or to the jaw, and it is often accompanied by diaphoresis, nausea, vomiting, or dyspnea. The pain may last for a few minutes (usually between 10 and 20 minutes) and relapse, as in cases of unstable angina, or about 30 minutes, as in cases of acute myocardial infarction. ${ }^{5}$

Chronic post-thoracotomy pain is a common condition, observed in $67 \%$ of the patients who underwent this procedure; according to Fabregat, ${ }^{34} 38 \%$ of these individuals still 
report pain $>3$ years later. Most patients complain of mild to moderate pain, but $>5 \%$ describe it as severe and/or incapacitating. Several clinical studies report positive long-term results with neuromodulation to control this type of pain.

The etiology of post-thoracotomy pain, although not fully understood, is related to the mechanical trauma of chest opening, which directly damages nerve bundles. Moreover, there is a secondary injury to the thoracic vascular network. In addition, the existence of a visceral component in pain formation is confirmed in more than half of the cases.

Until recently, chronic visceral pain was characterized as somatic and nociceptive pain, and therefore, not amenable to treatment by spinal cord electrical stimulation (SCES). However, recent evidence indicates that chronic visceral pain may not be nociceptive, but rather neuropathic in nature. ${ }^{9,10}$ The viscera have fewer nerve endings compared with the skin, and involvement is usually multisegmental. Refractory angina, which affects more than 6 million Americans, is an example of visceral pain. ${ }^{11}$

Traditionally, nociception passes through peripheral or first-order neurons (such as the celiac plexus) - which synapses with the second-order neurons from the dorsal horn of the spinal cord - and ascends through the lateral spinoreticular and/or the spinothalamic tract. ${ }^{12}$

In recent years, there have been important advances in angina treatment, both in pharmacological and reperfusion techniques (angioplasty or surgery). In 1999, the American Heart Association defined angina pectoris as a clinical syndrome characterized by discomfort in the chest, in the chin, in the shoulder, in the back, or in the arm, usually intensified by exertion or by emotional stress, ${ }^{13}$ whereas refractory angina was defined according to the lack of control of painful symptoms even when the therapies previously described are associated. ${ }^{14}$

Spinal cord electrical stimulation has been traditionally applied for the treatment of neuropathic pain, with good to excellent results. Visceral pain syndrome can be as debilitating and disabling as somatic or neuropathic pain; however, there seems to be a lack of consensus on the appropriate treatment and strategies for these disorders. ${ }^{10,15,16}$

Neurostimulation is a revolutionizing functional surgery because it has modulatory purposes and low risk. Thus, it has been used to treat a variety of conditions, including regional complex syndrome, postlaminectomy syndrome, peripheral vascular disease, neuropathic pain, refractory angina and, more recently, visceral pain and chronic pelvic pain. ${ }^{11}$ Moreover, several clinical studies report its effectiveness.

Although analgesic SCES was proposed by Shealy et al in $1967,{ }^{17}$ it was only in 1987 that Murphy et $a^{35}$ described the first case of refractory angina. ${ }^{14,18}$ Several controlled studies have confirmed the efficacy of SCES in the control of ischemic pain, mainly in limbs, but they have also demonstrated the lack of statistical difference compared with amputation. Spinal cord electrical stimulation, however, provided pain relief, increased locomotion capacity, and improved overall limb function and quality of life. ${ }^{19}$ Jivegard et $\mathrm{al}^{36}$ demonstrated the benefit to 51 patients with severe inoperable limb ischemia, followed-up for 18 months, and found out that their amputation-free survival (62\%) was higher compared

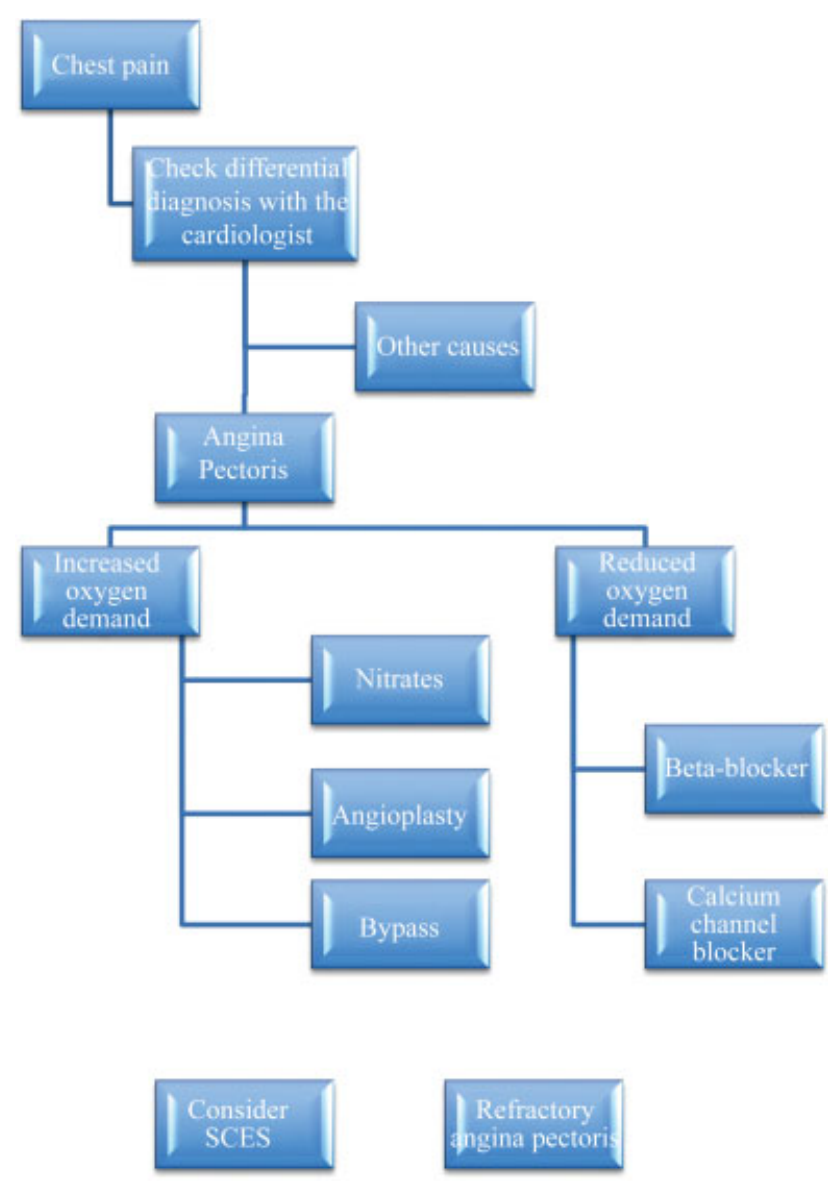

Fig. 1 Flowchart for the indication of spinal cord electrical stimulation (SCES) in patients with refractory angina.

with that of the control group (45\%), with a statistically significant difference $(p>0.05){ }^{19}$

In 2000, Ceballos et al were the first to use analgesic neurostimulation for visceral pain in a patient with chronic mesenteric ischemia-induced pain. ${ }^{13}$ In 2004, Krames et al ${ }^{20}$ reported a case of stimulation for irritable bowel syndrome.

Pain management in refractory angina was investigated by two prospective randomized studies about SCES. ${ }^{9,14}$ The results demonstrated a better ability and quality of exercise in the group submitted to SCES compared with the control group. $^{21,22}$

A prospective, randomized, comparative study between SCES and myocardial revascularization with 104 patients and a 5-year follow-up period performed by Mannheimer et al $^{37}$ demonstrated that angina symptoms and quality of life improved in both groups; however, mortality was higher in the revascularization group..$^{23,24}$ Today, its effectiveness is considered under category $2 \mathrm{~B}+.^{24}$

The flowchart below may help in cases of refractory angina and the best indication for SCES in these patients ${ }^{24}$ (-Fig. 1).

In Brazil, SCES is indicated mainly for complex regional syndrome and postlaminectomy syndrome cases. Mekhail et al $^{11}$ demonstrated the incidence of SCES in 707 patients, as shown in the graph below (-Fig. 2 ). 


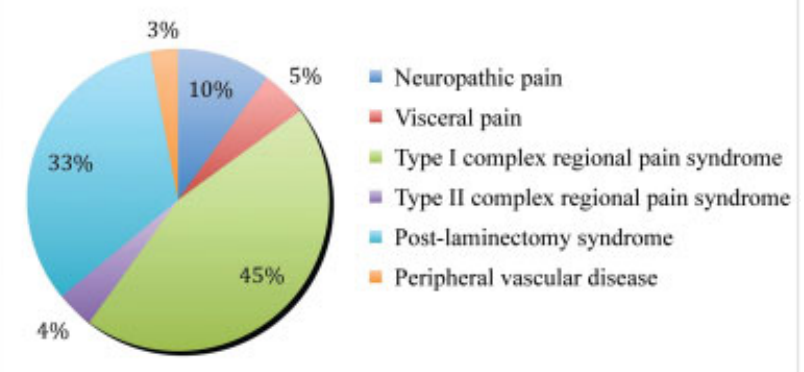

Fig. 2 Incidence of indication of spinal cord electrical stimulation (SCES). Source: Mekhail et al., 2011.11

\section{Clinical Example}

W. M., 61 years old, male, with a history of ischemic heart disease since 2011 and 2 acute myocardial infarctions (AMIs). After the ischemic events, he presented with angina and, despite extensive therapy, pain control was unsuccessful. The patient underwent two angioplasty procedures and a coronary artery bypass grafting with three saphenous conduits, resulting in the same outcome.

In order to reduce pain, a new angioplasty was performed, this time with a drug-coated stent; however, the pain persisted.

The three catheterizations reports are the following:

June 27, 2012:

1. Right coronary artery with a severe, $80 \%$ lesion in its medial third (intrastent restenosis).

2. Right coronary artery posterior descending branch with a moderate, $50 \%$ ostial lesion.

3. Anterior descending artery with a severe, 90 to $95 \%$ ostial lesion.

4. First diagonal branch (moderate significance) with a subocclusive, $95 \%$ ostial lesion.

5. Second diagonal branch (significant) with a moderate, $50 \%$ lesion at its proximal third (intrastent restenosis).

6. Circumflex artery with a subocclusive (98\%) ostial lesion (intrastent restenosis).

October 4, 2012:

1. Right coronary artery with a severe, $80 \%$ lesion in its medial third (intrastent restenosis).

2. Anterior descending artery with a severe, 90 to $95 \%$ ostial lesion.

3. First diagonal branch (moderate significance) with a severe, $90 \%$ ostial lesion.

4. Second diagonal branch (significant) with a moderate, $50 \%$ lesion at its proximal third (intrastent restenosis).

5. Circumflex artery with a subocclusive (98\%) ostial lesion (intrastent restenosis)

6. Saphenous graft between the aorta and the marginal branches with no significant lesions.
7. Saphenous graft between the aorta and the posterior descending artery with no significant lesions.

8. Severe, $80 \%$ lesion at the anastomosis between the left mammary artery and the anterior descending artery.

January 5, 2013:

1. Right coronary artery with a severe, $80 \%$ lesion in its medial third (intrastent restenosis).

2. Anterior descending artery with a severe, 90 to $95 \%$ ostial lesion.

3. First diagonal branch (moderate significance) with a severe, $90 \%$ ostial lesion.

4. Second diagonal branch (significant) with a moderate, $50 \%$ lesion at its proximal third (intrastent restenosis).

5. Circumflex artery with a subocclusive (98\%) ostial lesion (intrastent restenosis)

6. Saphenous graft between the aorta and the marginal branches with no significant lesions.

7. Saphenous graft between the aorta and the posterior descending artery with no significant lesions.

8. Patent left mammary artery anterior descending artery and stent with a good angiographical aspect.

After a new catheterization, no vascular lesion warranted the condition, and a functional analysis was initiated for pain control.

Thus, the patient was referred to the functional neurosurgery department of the Hospital Dilson Godinho, in Montes Claros, state of Minas Gerais, Brazil. The patient complained of a continuous, burning pain in a neuropathic pattern, worsening with physical exertion, in the anterior region of the left hemithorax; pain intensity, determined by the verbal numerical scale (VNS), ranging from 0 (absence of pain) to 10 (the most intense pain imagined by the patient), was rated as 5 . The patient was being treated with atenolol, $50 \mathrm{mg}$, every 12 hours; Sustrate (propatylnitrate), $10 \mathrm{mg}$, every 12 hours; hydrochlorothiazide, $25 \mathrm{mg}$, once a day; Adalat oros (nifedipine), $30 \mathrm{mg}$, once a day; gabapentin, $600 \mathrm{mg}$, every 8 hours; nortriptyline, $25 \mathrm{mg}$, at night; and tramadol, $100 \mathrm{mg}$, when in severe pain.

The patient also reported that walking small distances, of $<100 \mathrm{~m}$, caused his pain to change pattern, characterizing it as a sting with VNS $=8$, and requiring frequent pauses.

After the psychological evaluation, which did not identify any psychical contraindication for the surgical procedure, it was decided to implant a medullary neurostimulator with a $5 \times 6 \times 5$ electrode (Medtronic, Minneapolis, MN, USA) at the T2 spinous process level.

The procedure was performed in August 2014. The electrode was placed in contact with the posterior aspect of the spine through a microlaminectomy, with a $\sim 6-\mathrm{cm}$ skin access, 1 to 2 levels below the desired level.

After 2 months, the programming $(35 \mathrm{~Hz}, 2.4 \mathrm{~V}, 60$ milliseconds) had been reached and is sustained until now. A myocardial scintigraphy performed on February 02, 2015 showed normal conditions, with no ischemic and/or cicatricial lesions in the left ventricular myocardium. 


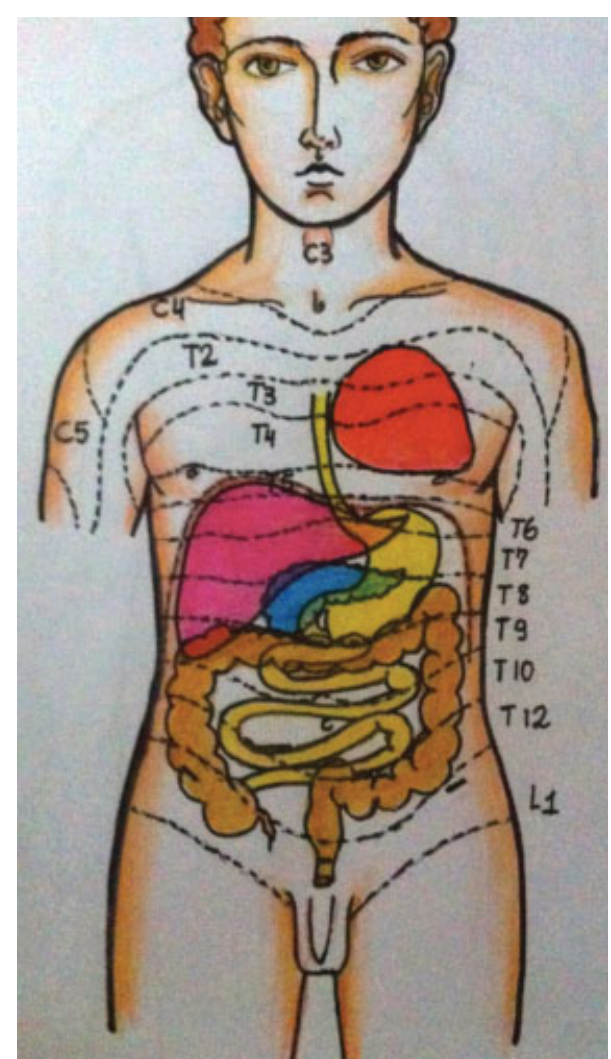

Fig. 3 This adapted figure ${ }^{33}$ schematically represents the table above.

Table 1 Summary of organs and respective spine levels for spinal cord electrical stimulation

\begin{tabular}{|c|c|c|}
\hline Target organ & Level & Note \\
\hline Pancreas & T7/T8 & Midline \\
\hline Liver & T6 to T9 & $\begin{array}{l}\text { Midline or lateralized } \\
\text { (right) }\end{array}$ \\
\hline Stomach & T6 to T9 & $\begin{array}{l}\text { Midline or lateralized } \\
\text { (left) }\end{array}$ \\
\hline $\begin{array}{l}\text { Ascending } \\
\text { colon }\end{array}$ & T9 to L1 & $\begin{array}{l}\text { Midline or lateralized } \\
\text { (right) }\end{array}$ \\
\hline $\begin{array}{l}\text { Transverse } \\
\text { colon }\end{array}$ & T9/T10 & Midline \\
\hline $\begin{array}{l}\text { Descending } \\
\text { colon }\end{array}$ & T9 to L1 & $\begin{array}{l}\text { Midline or lateralized } \\
\text { (left) }\end{array}$ \\
\hline Heart & $\begin{array}{l}\mathrm{T} 2 \text { to } \mathrm{T} 4\left({ }^{*} \mathrm{C} 7\right. \\
\text { to } \mathrm{T} 1)\end{array}$ & $\begin{array}{l}\text { Midline or lateralized } \\
\text { (left) }\end{array}$ \\
\hline
\end{tabular}

*Some reports indicate that this level would be more efficient. ${ }^{13}$

\section{Discussion}

The major difference in spinal stimulation for visceral pain compared with postlaminectomy syndrome or with regional complex syndrome is the number of stimulated dermatomes. In most viscera, the somatotopic arrangement has two to four medullar levels, sometimes requiring laterality.
Since some electrodes have a size limiter, the positioning, the choice of material, and the correct case selection are critical to positive outcomes and patient satisfaction.

Visceral diseases are often manifested by secondary hyperalgesia in the dermatomes provided by the same spinal segments supplying the viscera. This hyperalgesia may involve all dermatomes or only a specific part. ${ }^{25}$

Latif $^{24}$ states that, pathologically, unstable angina does not correlate with the extent of previous coronary stenosis. The lesion results from the temporary formation of thrombus, which is mediated by a complex cascade of cellular interactions between the vascular endothelium and platelets in the atherosclerotic coronary artery, ${ }^{26}$ leading to an imbalance between myocardial oxygen supply and demand that causes ischemia, injury, and, consequently, pain. ${ }^{27}$

Physiologically, SCES provides analgesia through its action on the segmental neuronal units of the spinal cord, leading to the antidromic excitation of the posterior funiculus fibers or nonspecific sensory conduction pathways of the spinal cord. Its activation causes a perception of paresthesia that is associated with the obtained analgesia. ${ }^{8,28}$

The beneficial effect of SCES on vascular pain and on peripheral ischemic pain is to promote the rebalancing of oxygen supply and demand, repairing and attenuating additional ischemic effects. ${ }^{9,12}$ Increased stimulation levels, resulting from antidromic activation, activate the afferent fibers from the dorsal roots, leading to the peripheral release of nitric oxide and calcitonin gene-related polypeptide (PRGC), which produces cutaneous vasodilation. ${ }^{21,29}$

There is also an inhibition of wide-dynamic-range (WID) neurons, previously activated by the lesion, thus reducing their algiogenic action. ${ }^{22}$ Some studies have shown that neuronal hyperexcitability is related to low GABA levels and that, after SCES, this neurotransmitter is normalized and the level of its excitatory analogue, glutamate, is reduced. ${ }^{22}$

Stimuli that do not generate a paresthetic effect may have a beneficial sympatholytic effect, better demonstrated in studies on refractory angina. ${ }^{30}$

Visceral pain treatment depends on a combination of pharmacological therapy with cognitive and behavioral therapies, as well as lifestyle changes. In addition, the pain secondary to low blood flow requires its restoration or improvement of oxygenation, which is not always possible with conventional surgeries. ${ }^{9}$

The use of transcutaneous electrical nerve stimulation (TENS) and of SCES for the treatment of type I complex regional pain syndrome (reflex sympathetic dystrophy) has been extensively documented. Because of this association between SCES and a sympathetically-mediated pain syndrome, SCES can be theoretically applied to the treatment of visceral pain, which is probably similarly mediated $^{7,16,25}$ (-Fig. 3).

- Table 1 summarizes the target organs and the medullary level to be stimulated.

The rate of SCES complications ranges from 30 to $40 \%$. Electrode migration is one of the most common complications, with an incidence of 13.2 to $22.6 \%$. 71 
Electrode migration is defined as the displacement of its desired original location, and it is caused by mechanical stress, increased mobility (cervical region), inadequate surgical fixation technique, trauma, infection, and muscle spasm, and it results in the loss of effective stimulation. This complication increases the risk of infection at review surgeries, and it also increases costs. ${ }^{7}$

Dural fistula, headache, neurological deficit, medullary compression, hemorrhage, epidural fibrosis, system malfunction (considered by many the most frequent complication, with an incidence ranging from 20 to $25 \%$ ), electrode or connection fractures are other examples of complications. $^{31-33}$

\section{Conclusion}

Spinal cord electrical stimulation is now a viable, low-risk option with satisfactory results for the treatment of neuropathic and visceral pain and, therefore, it can be used in refractory angina. With this purpose, today SCES is indicated after the failure of standard therapy, resulting in significant pain control and in improvement of the quality of life. However, further studies are required to increase the application and efficacy of this procedure in the clinical practice.

\section{Conflicts of Interests}

The authors have no conflicts of interests to declare.

\section{References}

1 Ishitani LH, Franco GdaC, Perpétuo IH, França E. [Socioeconomic inequalities and premature mortality due to cardiovascular diseases in Brazil]. Rev Saude Publica 2006;40(04):684-691

2 World Health Organization. Death and disability due to CVDs (heart attacks and strokes). In: Global Atlas on Cardiovascular Disease Prevention and Control. Mendis S, Puska P, Norrving B (Editors)., Geneva2011

3 Ministério da Saúde. Departamento de Informática do SUS. Available at http://www2.datasus.gov.br/DATASUS/index.php? area1/40201. Acesso em 04 de abril de 2014

4 Gowdak LHW. Angina estável. Rev Bras Med 2013;13(70):22-31

5 Bassan R, Pimenta L, Leães PE, Timerman A. Sociedade Brasileira de Cardiologia. I Diretriz de Dor Torácica na Sala de Emergência. Arq Bras Cardiol 2002;79(supl II):1-22

6 Crea F. Chronic ischaemic heart disease. In: ESC Textbook of Cardiology. Oxford: Oxford University Press; 2010

7 Kumar K, Taylor RS, Jacques L, et al. The effects of spinal cord stimulation in neuropathic pain are sustained: a 24-month follow-up of the prospective randomized controlled multicenter trial of the effectiveness of spinal cord stimulation. Neurosurgery 2008;63(04):762-770, discussion 770

8 Wijns W, Kolh P, Danchin N, et al. Task Force on Myocardial Revascularization of the European Society of Cardiology (ESC) and the European Association for Cardio-Thoracic Surgery (EACTS). European Association for Percutaneous Cardiovascular Interventions (EAPCI). Guidelines on myocardial revascularization. Eur Heart J 2010;31(20):2501-2555

9 Krames ES, Foreman R. Spinal Cord Stimulation Modulates Visceral Nociception and Hyperalgesia via the Spinothalamic Tracts and the Postsynaptic Dorsal Column Pathways: A Literature Review and Hypothesis. Neuromodulation 2007;10(03): 224-237
10 Oakley JC, Krames ES, Prager JP, et al. A new spinal cord stimulation system effectively relieves chronic, intractable pain: a multicenter prospective clinical study. Neuromodulation 2007;10(03): 262-278

11 Mekhail NA, Mathews M, Nageeb F, Guirguis M, Mekhail MN, Cheng J. Retrospective review of 707 cases of spinal cord stimulation: indications and complications. Pain Pract 2011;11(02): 148-153

12 Tiede JM, Ghazi SM, Lamer TJ, Obray JB. The use of spinal cord stimulation in refractory abdominal visceral pain: case reports and literature review. Pain Pract 2006;6(03):197-202

13 Ceballos A, Cabezudo L, Bovaira M, Fenollosa P, Moro B. Spinal cord stimulation: a possible therapeutic alternative for chronic mesenteric ischaemia. Pain 2000;87(01):99-101

14 García-Moll M, Serra R, García-Moll X. [Refractory angina treated by spinal cord stimulation. The results of a long-term follow-up]. Rev Esp Cardiol 2000;53(03):321-326

15 Khan YN, Raza SS, Khan EA. Application of spinal cord stimulation for the treatment of abdominal visceral pain syndromes: case reports. Neuromodulation 2005;8(01):14-27

16 Kapural L, Nagem H, Tlucek H, Sessler DI. Spinal cord stimulation for chronic visceral abdominal pain. Pain Med 2010;11(03): 347-355

17 Shealy CN, Mortimer JT, Reswick JB. Electrical inhibition of pain by stimulation of the dorsal columns: preliminary clinical report. Anesth Analg 1967;46(04):489-491

18 Taylor RS, De Vries J, Buchser E, Dejongste MJL. Spinal cord stimulation in the treatment of refractory angina: systematic review and meta-analysis of randomised controlled trials. BMC Cardiovasc Disord 2009;9:13

19 Deer TR, Raso LJ. Spinal cord stimulation for refractory angina pectoris and peripheral vascular disease. Pain Physician 2006;9 (04):347-352

20 Krames E, Mousad DG. Spinal cord stimulation reverses pain and diarrheal episodes of irritable bowel syndrome: a case report. Neuromodulation 2004;7(02):82-88

21 Buonocore M, Bonezzi C, Barolat G. Neurophysiological evidence of antidromic activation of large myelinated fibres in lower limbs during spinal cord stimulation. Spine 2008;33(04): E90-E93

22 Linderoth B, Foreman RD, Meyerson BA. Mechanisms of Spinal Cord Stimulation in Neuropathic an Ischemic Pain Syndromes. Neuromodulation 2009;25:345-354

23 van Kleef M, Staats P, Mekhail N, Huygen F. 24. Chronic refractory angina pectoris. Pain Pract 2011;11(05):476-482

24 Latif OA, Raj PP. Spinal cord stimulation: a comparison of efficacy versus other novel treatments for refractory angina pectoris. Pain Pract 2001;1(01):36-45

25 Kapural L, Deer T, Yakovlev A, et al. Technical aspects of spinal cord stimulation for managing chronic visceral abdominal pain: the results from the national survey. Pain Med 2010;11(05): 685-691

26 Hawiger J. Formation and regulation of platelet and fibrin hemostatic plug. Hum Pathol 1987;18(02):111-122

27 Tousoulis D, Androulakis E, Kontogeorgou A, et al. Insight to the pathophysiology of stable angina pectoris. Curr Pharm Des 2013; 19(09):1593-1600

28 Mensah GA, Brown DW. An overview of cardiovascular disease burden in the United States. Health Aff (Millwood) 2007;26(01): 38-48

29 Sindou MP, Mertens P, Bendavid U, García-Larrea L, Mauguière F. Predictive value of somatosensory evoked potentials for longlasting pain relief after spinal cord stimulation: practical use for patient selection. Neurosurgery 2003;52(06):1374-1383, discussion 1383-1384

30 Eddicks S, Maier-Hauff K, Schenk M, Müller A, Baumann G, Theres H. Thoracic spinal cord stimulation improves functional status and relieves symptoms in patients with refractory angina 
pectoris: the first placebo-controlled randomised study. Heart 2007;93(05):585-590

31 Taylor RS. Spinal cord stimulation in complex regional pain syndrome and refractory neuropathic back and leg pain/failed back surgery syndrome: results of a systematic review and metaanalysis. J Pain Symptom Manage 2006;31(4, Suppl)S13-S19

32 Eliasson T, Augustinsson LE, Mannheimer C. Spinal cord stimulation in severe angina pectoris-presentation of current studies, indications and clinical experience. Pain 1996;65(2-3):169-179

33 Kapural L, Cywinski JB, Sparks DA. Spinal cord stimulation for visceral pain from chronic pancreatitis. Neuromodulation 2011; 14(05):423-426, discussion 426-427
34 Fabregat G, et al Subcutaneous Botulinum Toxin for Chronic PostThoracotomy Pain. Pain Practice 2013;13(03):231-234

35 Murphy DF, Giles KE. Intractable angina pectoris: management with dorsal column stimulation. Med J Aust 1987;146: 260

36 Jivegard LE, Augustinsson LE, Holm J, Risberg J, Ortenwall P. Effects of spinal cord stimulation (SCS) in patients with inop- erable severe lower limb ischaemia: a prospective randomised controlled study. Eur J Vasc Endovasc Surg 1995;9:421-425

37 Mannheimer C, Eliasson T, Andersson B, et al. Effects of spinal cord stimulation in angina pectoris induced by pacing and possible mechanisms of action. Br Med J 1993;307:477-480 